\title{
Fracture process analysis of recycled aggregate concrete with combined acoustic emission and digital image correlation techniques
}

\author{
M. GUO", F. GRONDIN, S. Y. ALAM AND A. LOUKILI
}

\author{
LUNAM Université, Institut de Recherche en Génie Civil et Mécanique (GeM), UMR-CNRS 6183, Ecole \\ Centrale de Nantes, Nantes, France \\ e-mail: \{menghuan.guo ; frederic.grondin ; syed-yasir.alam ; ahmed.loukili\} @ec-nantes.fr
}

Key words: Recycled Aggregate Concrete, Fracture, Acoustic Emission, Digital Image Correlation

\begin{abstract}
The usage of recycled coarse aggregate (RCA) in concrete seems a good solution for the environmental protection and resources reservation problems. In this study, fracture process of both natural aggregate concrete (NAC) and recycled aggregate concrete (RAC) beams under threepoint bending tests were analyzed with combined acoustic emission (AE) and digital image correlation (DIC) techniques. The influence of RCA on the amplitude distribution and the absolute energy evolution of AE events over the entire loading were studied and a more brittle behaviour of RAC has been found. To check the reliability of AE and DIC results, the corresponding internal and external fracture parameters were defined; there exists a good agreement of the two methods. The two parameters are also proved to be very effective to reveal the internal and external fracture characteristics of NAC and RAC.
\end{abstract}

\section{INTRODUCTION}

The sustainability is one of the most pressing issues in many areas all over the world; the recycling of waste concrete has been promoted in the construction industry from the viewpoint of environmental protection and resources reservation. Numerous research projects have been performed to investigate the mechanical properties, durability, and the structural performance of recycled aggregate concrete (RAC). It is reviewed that RAC has high content of varied impurities and previous cracks [1]. Higher water absorption and lower density have been found for recycled concrete aggregates (RCA) [1]. Moreover, the RAC has a much more complicated microstructure compared to that of NAC [1]. Most of the studies find that the mechanical performance of RAC is usually poorer than that of natural aggregate concrete (NAC) [2-4].

The previous researches were mainly engaged in evaluating the mechanical strength of RAC. However, only the strength measurement will not guarantee the performance of concrete structure, because it depends also on the limitation of the crack opening to keep a good waterproofing. The determination of fracture properties is needed to provide more description of the potential loading-carrying capacity of the RAC. The objective of this work is to provide further insight to the recycled concrete performance under three point bending fracture test with the $\mathrm{AE}$ and $\mathrm{DIC}$ techniques.

\section{THE EXPERIMENTAL PROGRAM}

\subsection{Material properties}

Concrete mixtures were prepared with CEM II/A-L 42.5N, crushed limestone aggregates, and RCAs. RCAs were obtained by crushing unknown waste concrete. The fine aggregate used is crushed fine sand with a maximum size equal to $4 \mathrm{~mm}$. All the aggregates used in concrete mixtures are at saturated surface-dried state. Two different percentages of RCA in total mass of coarse aggregate in concrete mixtures ( 0 and 100\%) were used in this analysis. 
All the mixtures were designed to have the same cylinder compressive strength range of 25-30 MPa and the same workability defined by a slump of $20 \mathrm{~cm}$ after $15 \mathrm{~min}$ according to the structural class S4. Table 1 shows the mix quantities of constituent materials for the two types of concrete: $\mathrm{C}-\mathrm{N}-\mathrm{N}$ means the concrete with natural sand and natural coarse aggregate and $\mathrm{C}-\mathrm{N}-100 \mathrm{R}$ means the concrete with natural sand and $100 \%$ recycled coarse aggregate. The effective water-to-cement ratio is equal to 0.65 .

Table 1: Concrete mixture proportions

\begin{tabular}{ccc}
\hline Constituent $\left(\mathrm{kg} / \mathrm{m}^{3}\right)$ & C-N-N & C-N-100R \\
\hline Water & 180 & 189 \\
\hline Cement & 270 & 282 \\
\hline Sand 0/4 mm & 780 & 806 \\
\hline Gravel 6.3/20 mm & 820 & - \\
\hline Gravel 4/10 mm & 267 & - \\
\hline Recycled Gravel & - & 701 \\
$10 / 20 \mathrm{~mm}$ & & \\
\hline $\begin{array}{c}\text { Recycled Gravel } \\
\text { 4/10 mm }\end{array}$ & - & 163 \\
\hline
\end{tabular}

For the flexural test, $100 \times 200 \times 800 \mathrm{~mm}^{3}$ $(\mathrm{b} \times \mathrm{h} \times \mathrm{L})$ concrete beams were prepared with an effective span (S) equal to $600 \mathrm{~mm}$. The beams were notched at midspan with a notch depth $40 \mathrm{~mm}$. The notch was created using a metal plate of $1 \mathrm{~mm}$ thickness, placed into the mould before pouring of the concrete. The plate was removed with care after an initial curing period of 24 hours at $20^{\circ} \mathrm{C}$ and relative humidity of $95 \%$.

\subsection{Experimental techniques}

The fracture tests have been performed with a $160 \mathrm{kN}$ capacity servo-hydraulic machine. The load was applied by the crack mouth opening displacement (CMOD) control with a slow rate of $0.2 \mu \mathrm{m} / \mathrm{s}$, such that the peak load was reached at about $2 \mathrm{~min}$. Three beams for each class were tested. A general view of the experimental setup is provided in Figure 1.

The device for the acquisition and signal processing of $\mathrm{AE}$ is consisted of a data acquisition system MISTRAS 8 channels. Eight piezoelectric transducers with a frequency of $50-200 \mathrm{kHz}$ and a resonance frequency of $150 \mathrm{kHz}$ were placed on the beam around the expected location of the fracture process zone (FPZ). They form a rectangular position $\left(12 \times 12 \mathrm{~cm}^{2}\right)$ on each side of the specimen. The recorded AE signals were amplified by a $40 \mathrm{~dB}$ gain differential amplifier. A detection limit of $35 \mathrm{~dB}$ was chosen to overcome the background noise. The propagation velocity and the attenuation of acoustic wave were also calculated. The effective velocity was assumed to be $4400 \mathrm{~m} / \mathrm{s}$ for C-N-N and $4000 \mathrm{~m} / \mathrm{s}$ for C-N-100R. In order to eliminate mechanical and electromagnetic disturbances, a high pass filter with a cut-off frequency of $20 \mathrm{kHz}$, and a low-pass filter with a cut-of frequency of $400 \mathrm{kHz}$ were used. Each waveform was digitized and stored with AEwin ${ }^{\circledR}$ system. The descriptors were further analyzed and evaluated with Noesis ${ }^{\circledR}$ software.

In the experimental program, digital images were acquired continuously during the load test. The digital camera with $50 \mathrm{~mm}$ macro lenses was used to capture images of the beam. The digital camera has a resolution of $2452 \times$ 2056 pixels. Moreover, a speckle pattern of black and white paint was sprayed onto the surface of the specimen to improve the displacement resolution [5]. One lamp was used to improve the luminosity of the images. For each beam, the camera was mounted in order to image an area of approximately $110 \times$ $160 \mathrm{~mm}^{2}$ above the notch of the beam. At this location, notch opening and initial crack profile were captured. The resolution for each beam was about $72 \mu \mathrm{m} /$ pixel, which was considered sufficient to determine a displacement measurement with $2 \mu \mathrm{m}$ accuracy [5]. The images were taken at a rate of one image per second.

\section{EXPERIMENTAL RESULTS AND DISCUSSION}

\subsection{Mechanical properties of concrete}

The mechanical properties of concrete were determined at 28 days on $\varphi 110 \times 220 \mathrm{~mm}^{2}$ cylinders and the results are the average values of two specimens (Table 2). 
Table 2: Mechanical properties of concrete

\begin{tabular}{cccc}
\hline Concrete & $\begin{array}{c}f_{c 28} \\
(\mathrm{MPa})\end{array}$ & $\begin{array}{c}f_{t s p 28} \\
(\mathrm{MPa})\end{array}$ & $\begin{array}{c}E_{d y n} \\
(\mathrm{GPa})\end{array}$ \\
\hline C-N-N & $28.1 \pm 3.2$ & $2.48 \pm 0.03$ & $40.9 \pm 0.3$ \\
\hline C-N-100R & $25.2 \pm 0.3$ & $2.40 \pm 0.01$ & $33.1 \pm 0.5$ \\
\hline
\end{tabular}

As expected, the compressive strength, the splitting tensile strength and the dynamic elastic modulus decrease with the increase of RCA content. All of these can be explained by the lower stiffness and fracture energy in case of RAC.

Table 2 thus shows that the use of recycled materials does lower the compressive strength by $10 \%$ and the tensile strength by $3 \%$ compared to $\mathrm{C}-\mathrm{N}-\mathrm{N}$, which infers that the RAC has relatively brittle fracture behavior. With regard to the average curves of loadCMOD in Figure 2, the post-peak region of C$\mathrm{N}-\mathrm{N}$ falls more slowly compared to that of C$\mathrm{N}-100 \mathrm{R}$, demonstrating that $\mathrm{C}-\mathrm{N}-\mathrm{N}$ has a slightly better ductility.

\subsection{Localization of AE events in concrete}

The locations of the AE sources are shown in four stages of fracture test (Figure 2): $0-90 \%$ pre-peak, $90 \%$ pre-peak - $90 \%$ post-peak, $90 \%$ post-peak $-30 \%$ post-peak, and 30\% postpeak - $10 \%$ post-peak. The cumulated locations of acoustic events throughout the tests are shown in Figure 3 for the $\mathrm{C}-\mathrm{N}-\mathrm{N}$ and C-N-100R specimens. Each plotted point indicates a detected $\mathrm{AE}$ source and six levels of absolute energy $(0-50 \mathrm{aJ}, 50-100 \mathrm{aJ}, 100$ $-300 \mathrm{aJ}, 300-600 \mathrm{aJ}, 600-900 \mathrm{aJ}$ and >= $900 \mathrm{aJ})$ are divided during the four stages [6].

\subsection{Correlation of load-time curve and AE parameters}

The correlation between the load-time curve and the characteristics of $\mathrm{AE}$ signals collected during the flexure test is shown in Figure 4-7. The amplitude distribution $(\mathrm{dB})$ is calculated as the sum of the amplitudes in any given division of time. As demonstrated, the $\mathrm{AE}$ activity is weak during the initial loading stage both for concrete C-N-N and C-N-100R and few events are located.

Then for the second stage more events appear and the amplitude distribution increases quickly for the two concretes. Moreover, the $\mathrm{AE}$ events of $\mathrm{C}-\mathrm{N}-\mathrm{N}$ specimen unfold along the $\mathrm{y}$ position while for $\mathrm{C}-\mathrm{N}-100 \mathrm{R}$ the $\mathrm{AE}$ sources with high energy localize around the notch tip, which can be explained by the fact that the microcracks of $\mathrm{C}-\mathrm{N}-\mathrm{N}$ try to develop onward and those of $\mathrm{C}-\mathrm{N}-100 \mathrm{R}$ tend to coalesce with each other near the notch tip.

Another remarkable phenomenon is recorded during the third stage, where the crack tendency indicated by the events localization becomes very clear. The AE activity of RAC is more intense, indicating the formation of cracking bands. For C-N-N specimens, a plateau of the amplitude distribution exists while the amplitude distribution for $\mathrm{C}-\mathrm{N}-100 \mathrm{R}$ specimen drops obviously indicating a more brittle behaviour for RAC. Similarly, the energy rate jumps, representative of great needed driving force, occur also earlier for RAC.

In the terminal post-peak region numerous events are recorded, especially for $\mathrm{C}-\mathrm{N}-100 \mathrm{R}$ specimen. Accordingly, the amplitude distribution and the rate of the absolute $\mathrm{AE}$ energy decrease; however due to the different toughening mechanisms there exits also some AE events with high amplitude and energy. In addition, the final crack tendency is found to be similar with the DIC results [7].

\subsection{Evolution of FPZ and comparison with DIC results}

Since concrete is a heterogeneous material consisting of different phases, the elastic zone around a crack tip is termed as FPZ and dominated by complicated mechanisms such as crack shielding, crack deflection and aggregate bridging. It is important to understand and determine the size and the evolution process of FPZ, especially how it changes with the use of recycled coarse aggregate. The aim of the FPZ analysis is to compare the fracture characteristics for NAC and RAC.

The approach used here to analyze the properties of the FPZ is similar to that developed by [8]. The beam surface is divided 
into a two dimensional grid of square elements with uniform dimensions $\left(2 \times 2 \mathrm{~cm}^{2}\right)$. For each element the number of $\mathrm{AE}$ events is recorded. The cumulative number of events during each load step is plotted as a function of its vertical position $\mathrm{y}$ for various horizontal positions $\mathrm{x}$ over the height of the specimen. For example, the average curve for $\mathrm{C}-\mathrm{N}-\mathrm{N}$ at peak is presented on a continued line in Figure 8. The area between the average line and the position $y$ is defined as the internal fracture parameter $P_{i n}$ that can represent precisely the fracture state of specimen. Although the fracture parameters such as the length and width of FPZ have been used by many researchers $[5,9]$ to describe the cracking process of concrete. Here, attempts have been made to understand the fracture process in a two-dimensional way by defining the internal fracture parameter.

To check the effectiveness of the parameter, another similar external fracture parameter $P_{e x}$ by DIC technique is defined as the area between the crack profile and the position y, along the height of the beam (Figure 8). The developments of the two normalized parameters over the entire loading are calculated and compared (Figures 9-12).

Results of $\mathrm{AE}$ infer that the cracking activity of C-N-N begins earlier compared to that of C-N-100R until peak. In contrast, according to DIC, the crack of C-N-100R initiates earlier and develops always faster than that of C-N-N. Here, it should be reminded that the crack process recorded by $\mathrm{AE}$ is inside the specimen while the crack path calculated by DIC is on one surface of the specimen. These comparisons by the two methods show the differences of external and internal fracture features.

In addition, for $\mathrm{C}-\mathrm{N}-\mathrm{N}$ the external fracture parameter $P_{e x}$ is a bit higher than that of the internal fracture parameter $P_{i n}$ during the stage from $60 \%$ pre-peak to $80 \%$ post-peak, which implies that the cumulated internal cracking develops gradually in a similar way as the external cracking. Then, in the following phases the internal fracture becomes more significant. However, for C-N-100R the internal cracking activity is much lower than that of the external cracking activity from the very first loading to $70 \%$ post-peak. As shown in Figure 3, fewer acoustic events are recorded during this phase. It is also noted that the internal fracture parameter increases abruptly after peak, which means that the cracks propagate easily in the specimen of C-N-100R with less energy demand. A sudden failure may then appear. All of those confirm the more brittle behaviour of RAC as observed in the abovementioned amplitude distribution and the energy rate jumps of RAC.

It is also observed that there are more crushed coarse aggregates rather than the deboned coarse aggregates on the fracture surface of C-N-100R. Most of all, the fracture surface of C-N-N is much more tortuous and the cracks are more likely to pass by the natural coarse aggregates, while in C-N-100R the cracks tend to pass through the RCAs.

\section{CONCLUSIONS}

A quite satisfactory agreement between $\mathrm{AE}$ and DIC has been obtained considering that the two techniques rely on very different physical principles. It is possible to connect the surface cracking with the released elastic waves inside the specimen. Thus, the following conclusions can be made:

(1) The use of RCA reduces the mechanical properties of RAC.

(2) The decrease of the amplitude distribution after the peak load and the earlier energy rate jumps indicate a more brittle behaviour for RAC specimens.

(3) For C-N-N, the cumulated internal cracking develops gradually in a similar way as the external cracking during the initial loading and then the former becomes more significant.

(4) While for C-N-100R the internal cracking activity is relatively low at the beginning and it increases abruptly after peak with less energy demand.

(5) The parameters $P_{\text {in }}$ and $P_{e x}$ are very effective to reveal the differences of internal and external fracture characteristics.

However, a more thorough interpretation of the optical images and the $\mathrm{AE}$ waveforms is still needed for a better understanding of the 
degradation mechanisms of the RAC. Further studies will be presented in the future.

\section{REFERENCES}

[1] Xiao, J., Li, W., Fan, Y., and Huang, X. 2012. An overview of study on recycled aggregate concrete in China (1996-2011). Construction and Building Materials 31:364-383.

[2] Roesler, J.R., Cervantes, V., and Bordelon, A. 2009. Fracture properties of concrete containing recycled concrete aggregates. Magazine of Concrete Research 61(9):665-670.

[3] Casuccio, M., Torrijos, M.C., Giaccio, G., and Zerbino, R. 2008. Failure mechanism of recycled aggregate concrete. Construction and Building Materials 22:1500-1506.

[4] Manzi, S., Mazzotti, C., Bignozzi, M.C. 2013. Short and long-term behavior of structural concrete with recycled concrete aggregate. Cement Concrete Composites 37:312-318.

[5] Alam, S.Y., Saliba, J., and Loukili, A. 2014. Fracture examination in concrete through combined digital image correlation and acoustic emission techniques. Construction and Building Materials 69:232-242.

[6] Saliba, J., Loukili, A., Grondin, F., and Regoin, J.-P. 2012. Experimental study of creep-damage coupling in concrete by acoustic emission technique. Materials and Structures 45:1389-1401.

[7] Guo, M., Alam S.Y., Bendimerad, A., et al. 2016. Crack Propagation process of recycled concrete by digital image correlation. Submitted.

[8] Haidar, K., Pijaudier-Cabot, G., Dube J.F., Loukili, A. 2005. Correlation between the internal length, the fracture process zone and size effect in model materials. Materials and Structures 38:201-210.

[9] Skarzynski, L., Syroka, E., and Tejchman, J. 2009. Measurements and calculations of the width of the fracture process zones on the surface of notched concrete beams. Strain 47:319-332.

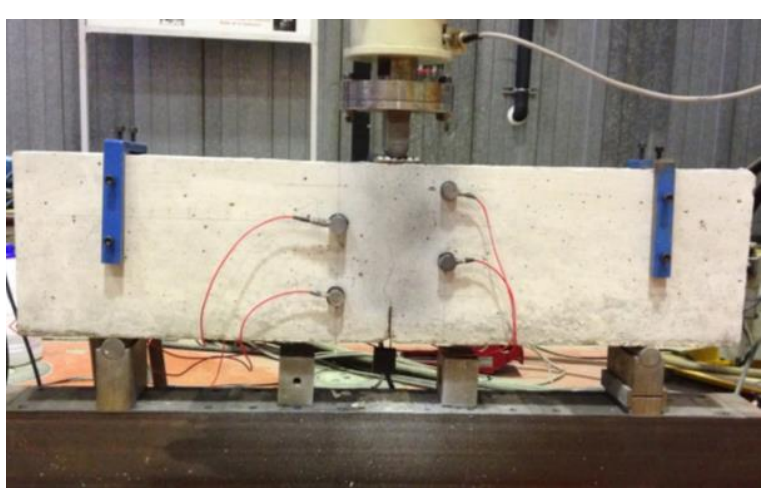

Figure 1: Experimental setup.

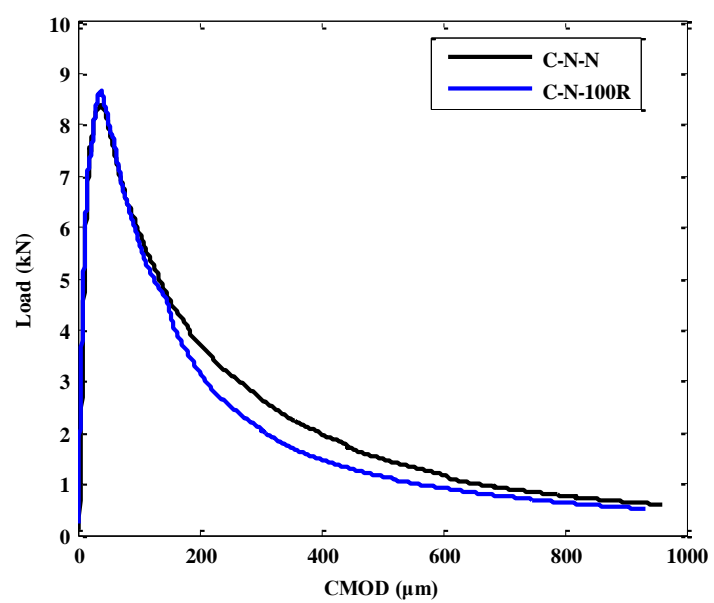

Figure 2: Load-CMOD curves. 

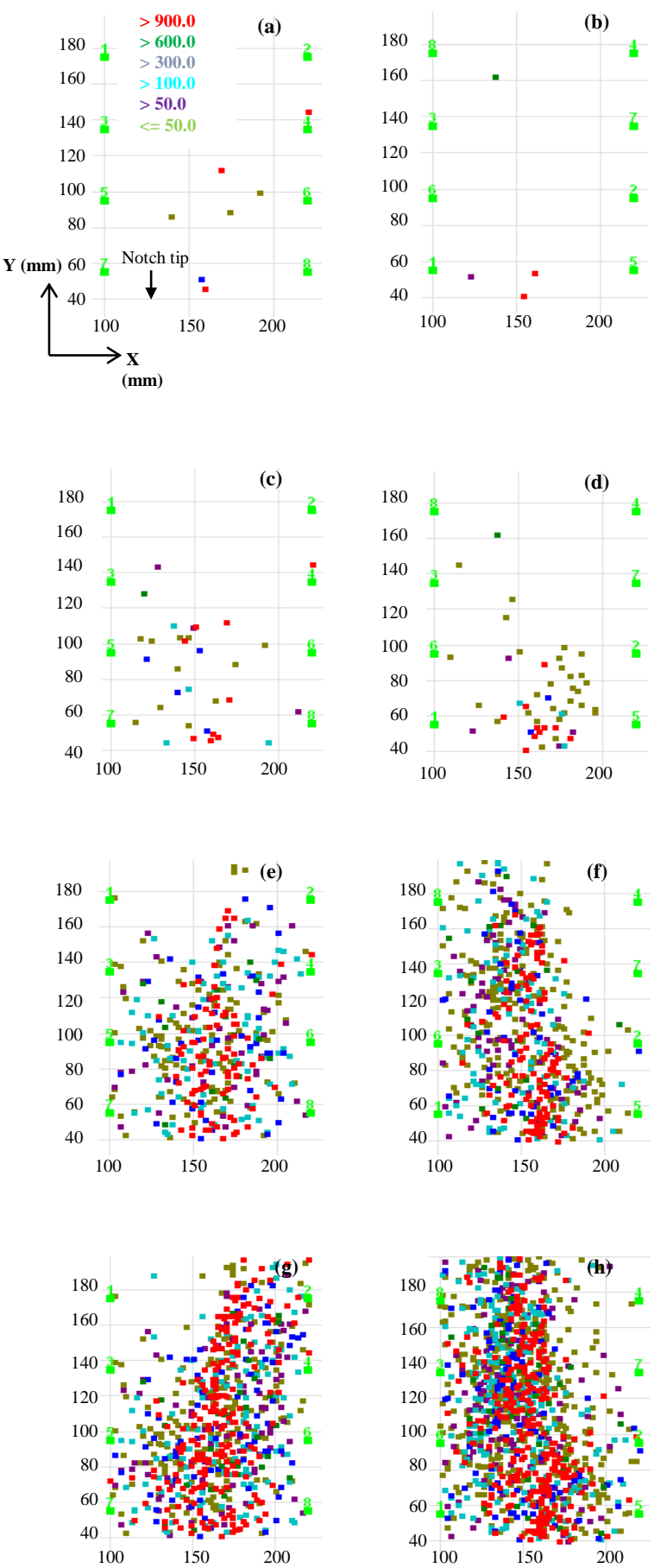

Figure 3: Localization of AE events for C-N-N (left) and C-N-100R (right): (a) and (b) 0-90\% pre-peak; (c) and (d) 90\% pre-peak - 90\% post-peak; (e) and (f) $90 \%$ post-peak - 30\% post-peak; (g) and (h) 30\% post-peak - $10 \%$ post-peak

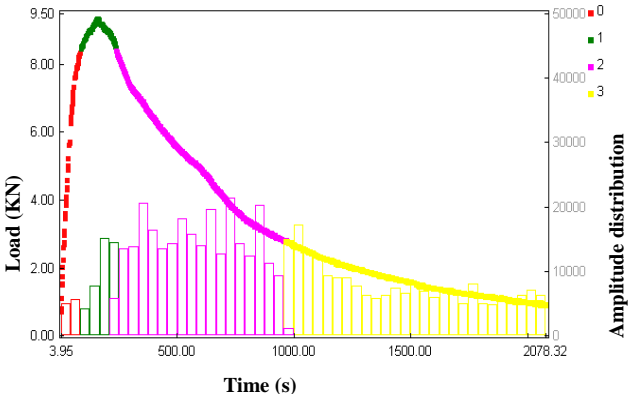

Figure 4: Correlation of load-time curve with $\mathrm{AE}$ amplitude distribution for C-N-N.

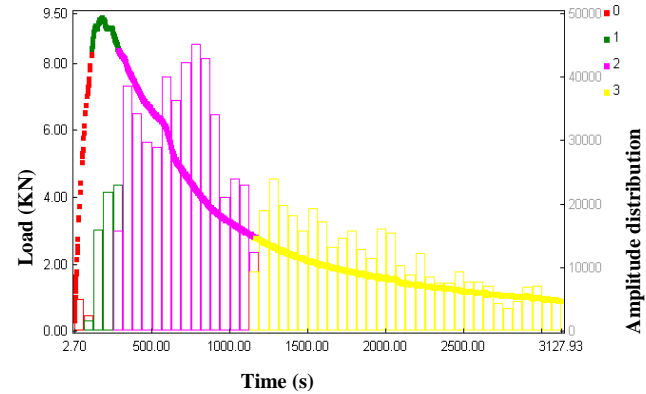

Figure 5: Correlation of load-time curve with $\mathrm{AE}$ amplitude distribution for C-N-100R.

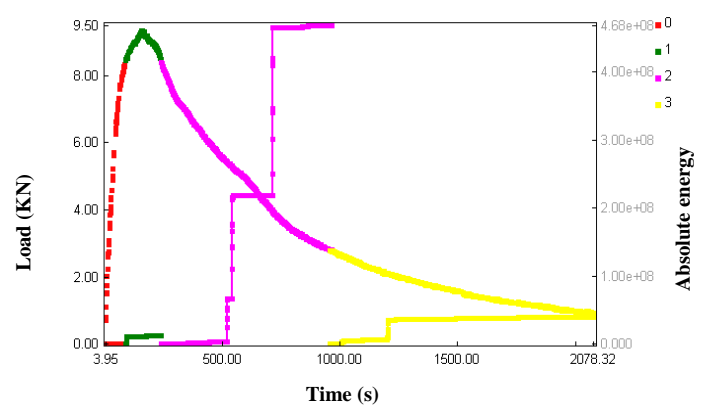

Figure 6: Correlation of load-time curve with $\mathrm{AE}$ energy rate for $\mathrm{C}-\mathrm{N}-\mathrm{N}$.

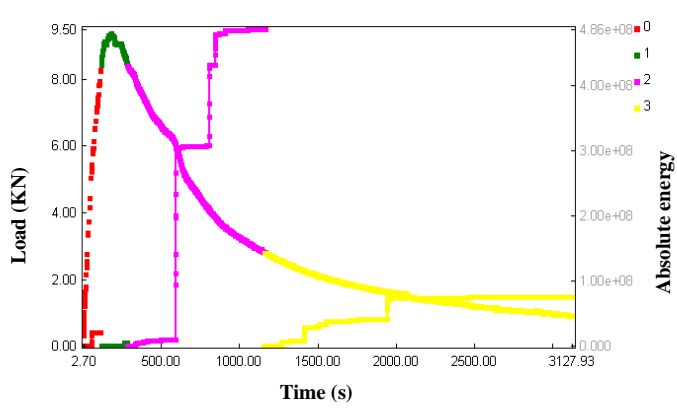

Figure 7: Correlation of load-time curve with $\mathrm{AE}$ energy rate for $\mathrm{C}-\mathrm{N}-100 \mathrm{R}$. 

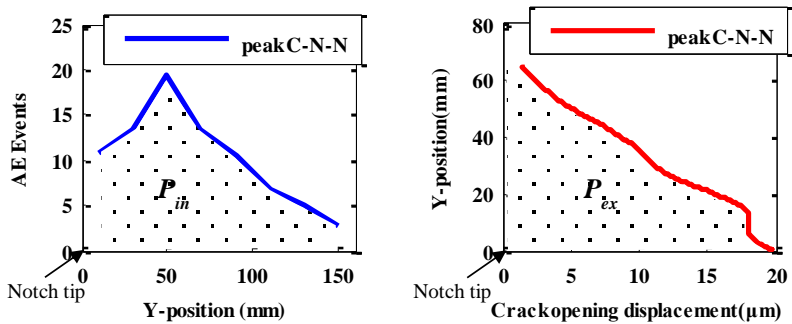

Figure 8: Schematic diagram of internal fracture parameter $P_{i n}$ and external fracture parameter $P_{e x}$.

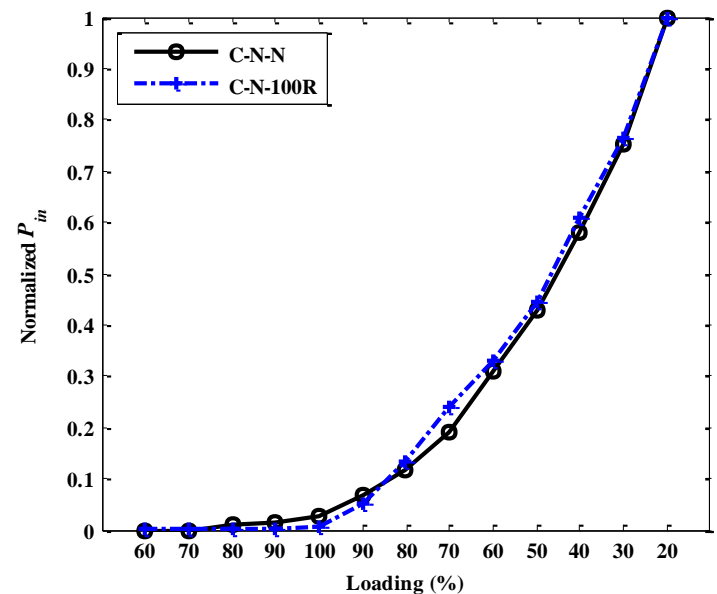

Figure 9: Development of the normalized internal fracture parameter $P_{\text {in }}$ with loading for C-N-N and C-N-100R.

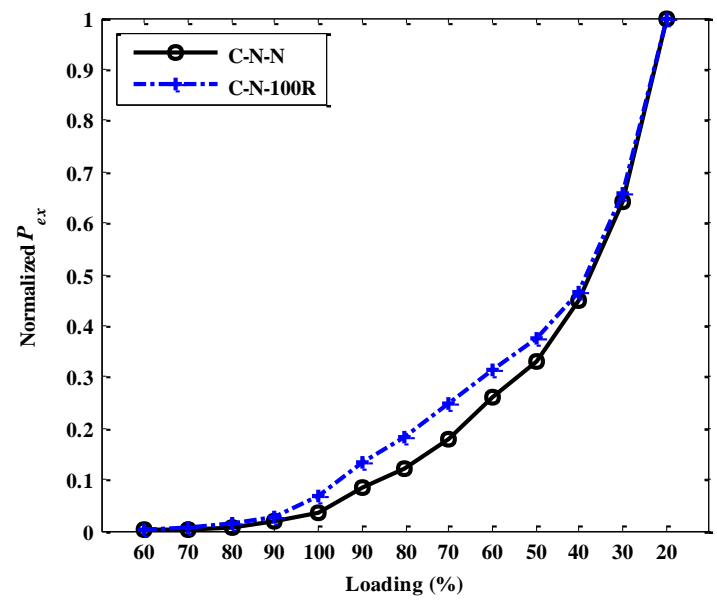

Figure 10: Development of normalized external fracture parameter $P_{e x}$ with loading for C-N-N and C-N-100R.

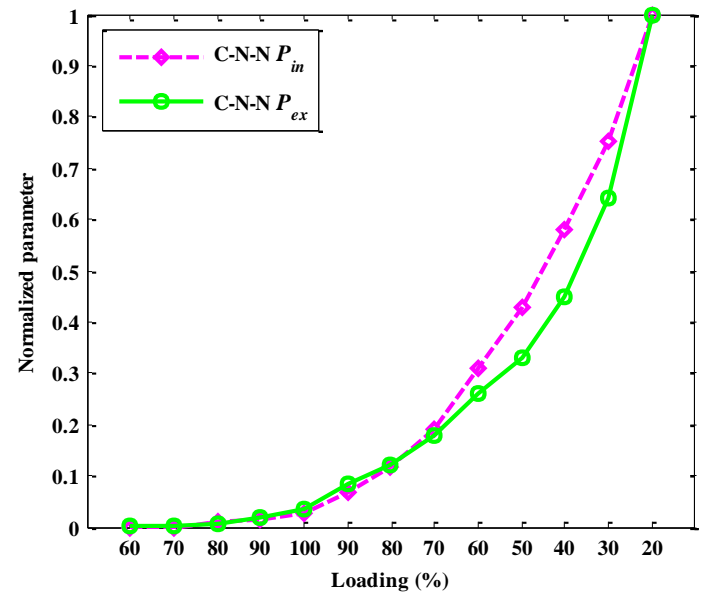

Figure 11: Comparisons of the development of normalized internal fracture parameter $P_{i n}$ and normalized external fracture parameter $P_{e x}$ for C-N-N.

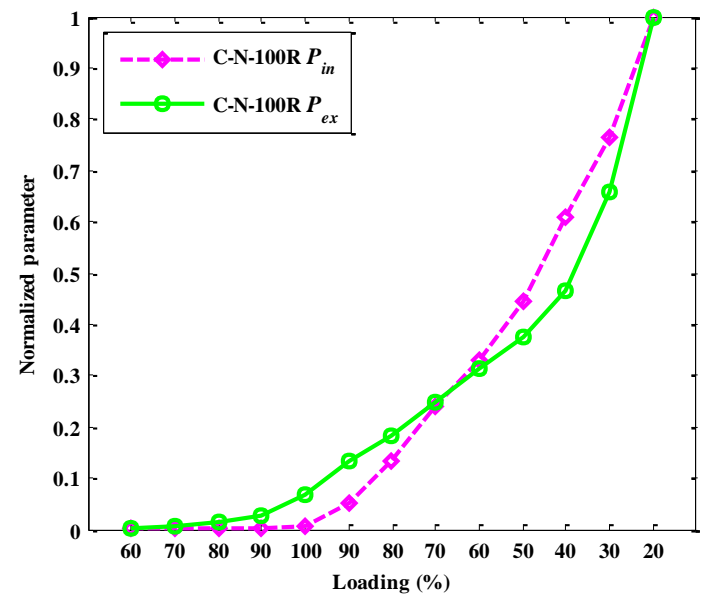

Figure 12: Comparisons of the development of internal fracture parameter $P_{i n}$ and external fracture parameter $P_{e x}$ for C-N-100R. 